\title{
NIETZSCHE EN LA ESCRITURA DE IMRE KERTÉSZ O CÓMO IR HACIENDO DESTINO EN UN MUNDO CONTINGENTE ${ }^{1}$ \\ Nietzsche in Imre Kertész's Texts, or How to make One's Way in a Contingent World
}

\author{
Jaime Aspiunza \\ Universidad del País Vasco
}

RESUMEN: Se entiende mejor la obra de Imre Kertész si se tienen en cuenta las principales preocupaciones nietzscheanas. Aquí en particular se rastrea la coincidencia del escritor con el filósofo en relación con 1) la concepción retórica del lenguaje, 2) la consideración del arte en cuanto función vital, y 3) la concepción de la temporalidad y la forja de un destino como realización de la existencia individual.

Palabras clave: lenguaje - arte - destino - muerte

ABSTRACT: By taking into account Nietzsche's main concerns we can understand much better the works by Imre Kertész. In this paper I search for agreements between the Hungarian writer and the German philosopher relative to 1) the rhetorical conception of language, 2) the view of art as a vital function, and 3) the conception of temporality, and the forging of fate as fulfillment of the individual existence.

Key words: Language - Art - Fate - Death

Imre Kertész, de origen judío, nace en Budapest en 1929, pasa una temporada entre 1944 y 1945 en campos de concentración alemanes, y vive otros cuarenta y cinco años en la Hungría comunista. El año 2002 recibe el premio Nobel de Literatura "por una obra que conserva la frágil experiencia del individuo frente a la bárbara arbitrariedad de la historia».

Según me decía en una entrevista, Nietzsche entró bastante tarde en su vida. Su formación de juventud es, más bien, la del existencialismo de postguerra; los autores que le llevaron a escribir fueron Th. Mann, Camus y Wagner. A lo que parece por las anotaciones de su Diario de la galera, no descuella Nietzsche hasta que Kertész, a mediados de 1984, acepta hacerse cargo de la traducción al húngaro de El nacimiento de la tragedia. Lee entonces Ecce homo ${ }^{2}$. Queda de

1. Este texto fue escrito en el marco de los proyectos de investigación «La expresión de la subjetividad en las artes» (HUM2005-02533) y «El testimonio en los genocidios del siglo XX. Una investigación estética» (EHU06/79), y leído en el I Congreso Internacional de la SEDEN, celebrado en Málaga los días 3-5 de abril de 2008.

2. Hasta entonces encontrábamos sólo dos anotaciones en que Nietzsche no salía muy bien parado, sendas comparaciones con Kant y con Kafka (Diario de la galera, pp. 33, de 1974, y 103, de enero de 1981). En enero de 1981 alude a La genealogía de la moral, cuando dice que Nietzsche, «al lado de Kafka, parece un burdo zopenco alemán». 
inmediato maravillado: «Ecce homo. Nietzsche, el Nietzsche del amor fati [...]. ¡Magnífico!» .

En las líneas siguientes se congratula de coincidir con Nietzsche en que el arte es una función vital del ser humano ${ }^{4}$. Y al concluir que para Nietzsche el «problema también era -iya en aquel entonces!- el individuo, la personalidad», acaba reconociéndose en él: «Siempre he pensado con Nietzsche — dice-, llevo sus problemas en la sangre. De ello se ocupa la realidad, mi experiencia: aquí no hay ninguna construcción, nada teórico» ${ }^{5}$.

$\mathrm{Al}$ acabar seis meses y medio después la traducción, en febrero de 1985, ve ya un destino en su encuentro con Nietzsche: "Yo tenía que traducir a Nietzsche. Las profundidades desde donde he venido a parar aquí. La realización apenas concebible. La primera sacudida cuando — hace lejanas décadas — oí hablar de este texto» ${ }^{6}$.

¿Lejanas décadas...? i¿Tanto?! iLa conmoción, al menos, venía de lejos!

Efectivamente, en un discurso del año 2000 trae a colación a Nietzsche en calidad de «maestro» ien la época en que sus obras estaban prohibidas en la Hungría socialista! ¿Desde cuándo, entonces? Repasamos de nuevo el Diario de la galera y hallamos otra referencia, ésta del año 1976, el de la crisis de donde saldrían Fiasco y Kaddish; otra vez Ecce homo: «El pesimismo perfecto sería aquel que comprende la mentira pero es al mismo tiempo incapaz de desprenderse de su ideal: abismo entre el querer y el conocer» ${ }^{7}$. Pesimismo de la fuerza.

Decía Nietzsche que en el filósofo «nada, absolutamente nada es impersonal» ${ }^{8}$. Su obra es buena muestra de ello. Esa misma reciprocidad de vida y escritura, esa honestidad de filólogo, que tiene por fruto una autenticidad radical de la existencia, se le puede igualmente atribuir a Kertész. Hasta el punto de que podríamos pedirle a Alexander Nehamas que nos prestara su título: Kertész. La vida como escritura. Pues la vida, su vida en cuanto individuo, es el único asunto; y su obra es lo que tal vida escribe.

Sea como sea, con Nietzsche se puede entender mucho mejor a Kertész, quizás entenderlo por primera vez. No sólo hay un parentesco espiritual o una misma actitud vital, con ser éstos importantísimos en su radicalidad y singularidad, sino que coinciden también en la concepción de unas cuantas cuestiones fundamentales, las sugeridas por el propio Kertész con relación a Nietzsche, que son las que a continuación voy a indagar:

1. La manera de entender y manejarse con el lenguaje: me refiero a la, llamémosla, concepción «retórica» del lenguaje por parte de Nietzsche. El lenguaje como mentira útil.

2. La consideración del arte como función vital.

3. La concepción de la temporalidad y la forja del destino en cuanto realización de la existencia individual, que Nietzsche recoge en la fórmula del amor fati.

3. I. Kertész, Diario de la galera, trad. de A. Kovacsics, Barcelona: Acantilado, 2004, p. 164.

4. Ibid., p. 165.

5. Ibid., p. 166.

6. Ibid., p. 169.

7. Ibid., p. 65.

8. MBM, trad. de A. Sánchez Pascual, Madrid: Alianza, ${ }^{7} 1982, \mathbb{S} 6$, p. 27. 


\section{LA CUESTIÓN DEL LENGUAJE}

Dossier K., su último libro, pretende ser a la vez autobiografía y novela: así nos lo dice Kertész en una breve "advertencia previa»" Y nos remite a Nietzsche, quien hacía derivar la novela de los diálogos platónicos ${ }^{10}$. Aun así, en las primeras páginas niega tajantemente que lo suyo (habla en particular de Sin destino, pero otro tanto valdría para sus demás novelas) sea novela autobiográfica. «Tal género - dice- no existe» ${ }^{11}$.

¿Con qué nos quedamos: son autobiografía y novela dos géneros inmiscibles o, por el contrario, según como se los mire, son indistinguibles el uno del otro? Esta aparente paradoja — que no es mero juego de palabras, sino clave de bóveda de toda su escritura- sólo se puede resolver - me parece-, si tenemos en cuenta lo que Nietzsche pensó acerca del lenguaje, la ficción y la realidad.

Si Nietzsche, en Sobre verdad y mentira..., advertía que el lenguaje no refleja la realidad «en sí», sino que sólo alude a ella, transponiéndola en significación —interpretándola - a través de un par de saltos metafóricos que vinculan «dos esferas absolutamente distintas", el mundo de los afectos y el de la palabra ${ }^{12}$; si, luego, en Aurora llegaba a sugerir que «vivir la vida es fabular, crear», dicho en alemán: Erleben ist ein Erdichten..., creo que Kertész se adheriría de pleno, y que sólo considerando esa doble tesis $-a$ ) de que el lenguaje no refleja la realidad, $b$ ) que, en consecuencia, en cuanto seres lingüísticos se da en nosotros cierta doblez o circularidad en algún modo hendida o rota que redunda en que vivimos y, además, dentro de ese vivir interpretamos ese vivir-; sólo considerando esa doble tesis podemos entender la paradoja de los géneros: no existe la «novela autobiográfica» porque no es posible mezclar un poco de realidad y un poco de ficción: en cuanto hablamos o escribimos estamos ya fabulando, creando. A la obra de Kertész, por otro lado, se le está llamando «novela autobiográfica» porque, siendo novela, se vale muy directamente de la materia prima de su experiencia, por ser, como dice Kundera de la novela en general, «una exploración [eso sí, muy personal e íntima] de lo que es la vida humana en la trampa en que hoy se ha convertido el mundo» ${ }^{13}$.

Y muy probablemente fue esa trampa — su reválida en Buchenwald y los cuarenta y cinco años de comunismo en Hungría- la que le hizo ver que el lenguaje no es homólogo de la realidad, que no dice la vida; desde luego, la experiencia del dolor y del sinsentido escapan a la palabra, poniéndola en evidencia, y el discurso totalitario descubre, al hipertrofiarla, la falsedad constitutiva del lenguaje.

En todo caso, el problema del lenguaje es algo que está siempre presente en la reflexión kertésziana. En marzo de 1990, ante la inminente muerte de su madre, escribe: «Un fenómeno estremecedor: el lenguaje habla desde el interior del ser humano. ¿Qué es el lenguaje? ¿Vela o desvela? Quizás más bien lo primero: vela el ser, al que interpreta como algo muy distinto, como lo radicalmente otro» ${ }^{14}$.

Pero no hace falta llegar a la muerte de la madre ni a 1990.

9. I. Kertész, Dossier K., trad. de A. Kovacsics, Barcelona: Acantilado, 2007, p. 5.

10. Cf. NT, trad. de A. Sánchez Pascual, Madrid: Alianza, ${ }^{5} 1980$, p. 121.

11. I. Kertész, Dossier K., cit., p. 11.

12. Cf. VME, trad. de L. M. Valdés, Madrid: Tecnos, ${ }^{5} 2007$, p. 30.

13. M. Kundera, El arte de la novela, trad. de F. de Valenzuela y M. V. Villaverde, Barcelona: Tusquets, 2000, p. 37.

14. I. Kertész, Diario de la galera, cit., p. 239. Cursiva mía. 
Ya en Sin destino, su primera obra, la cuestión del lenguaje es principal. Pienso en el tratamiento retórico que le dio a la novela para narrar la experiencia de los campos. La novela trata de articular la formación de un «sin-destino", de una «no-personalidad»: es el anti-Bildungsroman, la historia de la desposesión absoluta de György Köves, el niño de 14 años que llega a convertirse, como señala L. Földényi, en un simple hueco, en un espacio vacío ${ }^{15}$.

Sin destino no narra hechos ni experiencia subjetiva alguna, porque allí no hay sujeto alguno, sino el vaciado totalitario del sujeto. El niño viene a cumplir la función de una suerte de "sensorio común», da cuenta de la experiencia estética del mundo, y lo que sale a la luz es la conciencia de una sociedad ya en germen totalitaria. A través del narrador se ve lo que pasa, lo que va sucediendo; él no tiene nada que decir, «solamente lo hace hablar la tortura a la que lo somete el mundo ${ }^{16}$. Eso es lo que Kertész trata de presentarnos: el acontecer en su continuidad, lo que va llenando el tiempo. Pues el tiempo es el ritmo de nuestra existencia, y en el campo de concentración el tiempo se detiene y a la vez se acelera hasta el vértigo: no hay tiempo para nada, la vida pierde su referencia, se desencaja.

Pues bien, Kertész sólo encontró el lenguaje apropiado para narrar lo que entiende que es un estado general del hombre contemporáneo cuando se percató de la centralidad del tiempo: lo que pretende en Sin destino es crear una presencia continua, intensa, basada en la idea de que lo importante «es lo que va sucediendo y sucede en cada instante y son cosas pequeñas, banales, sin importancia... Eso es lo importante», me explicaba ${ }^{17}$. El destino de un hombre se va haciendo a través de todas esas cosas pequeñas y hasta sin importancia para las que de hecho no hay un lenguaje apropiado, y Nietzsche habría sido uno de los primeros en señalarlo... Interpretar la experiencia de los campos con grandes palabras nos impide entender lo que aquello significa: se habla del mal absoluto, de lo demoníaco, de la sinrazón y... «al fin y al cabo — como diría Kertész- para asesinar a millones de judíos, el estado total no necesita [...] sino buenos gestores» ${ }^{18}$.

$\mathrm{Y}$ es que el lenguaje de las grandes palabras, que sigue siendo el lenguaje entendido en cuanto representación, el que se supone que desvela esencias, hechos, etc., es un lenguaje que sigue preso de la supuesta oposición absoluta entre bien y mal, y demás contraposiciones equivalentes. El último capítulo de Sin destino nos hace ver la modificación del lenguaje a que da lugar la insistencia latente del tiempo: de vuelta en Budapest, en una conversación con unos vecinos, György les explica que lo que ha ocurrido no son cosas inconexas, caóticas, incomprensibles, acontecimientos que hubieran sucedido todos a la vez..., como se deduciría de su relato: «llegaron las estrellas», «llegaron los nazis», «llegó esto», «llegó lo otro»..., sino que todos íbamos dando pasos, pasos para sobrevivir. Y les habla de los veinte minutos de espera en la cola de la selección a la entrada de Auschwitz, cuando se decide si sigues o no con vida. Esos veinte minutos no es una cosa que pasa, son

15. Cf. I. Kertész, Sin destino, trad. de J. Xantus, Barcelona: Acantilado, 2001, p. 165; L. Földényi, «Der Identitätslose und sein Ich. Zehn Begriffe für ein Kertész-Wörterbuch»: Du 757 (2005), p. 42.

16. I. Kertész, Diario de la galera, cit., p. 31.

17. "Conversación con Kertész", entrevista realizada y traducida por J. Aspiunza, Archipiélago 82 (2008), número monográfico dedicado a I. Kertész, p. 12.

18. I. Kertész, Un instante de silencio en el paredón. El holocausto como cultura, trad. de A. Kovacsics, Barcelona: Herder, ${ }^{2} 2002$, p. 80. 
instante a instante, paso a paso, no hay momentos vacíos... Por eso, sobrevivir es de alguna manera colaborar. Todo lo que nos sucede en la vida puede ser importante, hasta lo que no lo parece. No es cosa de seguir dividiendo el mundo en lo esencial y lo accidental, lo necesario y lo contingente, etc. Pues la contingencia, una vez realizada, deviene necesidad, en algunos casos, destino.

Dicha concepción del tiempo, la de ese tiempo intenso, continuo presente pone, pues, en entredicho la oposición fundamental bueno/malo, víctima/verdugo, el lenguaje de los dualismos rígidos. Eso ha quedado claro a lo largo de la obra, y en Fiasco, su siguiente novela, será objeto de reflexión expresa. Allí, en discusión con Semprún, hace notar que la caracterización de los nazis como sujetos perversos impide ver el sistema totalitario, el «mundo organizado para el asesinato» ${ }^{19}$.

No se trata de negar la diferencia entre víctimas y verdugos, sino, por el contrario, de destacar la concordancia (quizás hasta connivencia) de ese lenguaje de la metafísica - lenguaje de sujetos y substancias- con los sistemas totalitarios. A las situaciones, al mundo de relaciones que Kertész quiere transmitir les corresponde un lenguaje más suelto, que no imponga rigideces, un lenguaje vivo, rico en matices para rescatar del olvido todo lo que pasa.

En Fiasco mismo asistimos al efecto liberador de esa concepción del lenguaje, y es que con él se puede jugar. La novela comienza así: «El viejo estaba sentado ante el secreter. Pensaba». Pues bien, no han transcurrido diez páginas y el narrador se apresta a explicar al lector el sentido del «léxico desenvuelto» - dice- que ha empleado desde el principio y que, por cierto, recuerda al Robert Walser de El paseo: "Así como, por ejemplo, el secreter no era un verdadero secreter, o, para citar otro ejemplo, la calle secundaria (la Quebrada de las Mentiras, que así la llamaba el viejo) tampoco era un verdadera calle secundaria, el viejo no era un verdadero viejo» ${ }^{20}$.

Aunque habría que estudiar mejor la ironía de Kertész... no insisto más. Baste con señalar cómo en la primera parte de la novela, en la que expone cómo se escribe una novela, se desmitifica el talento o el genio del artista, y se presenta la escritura como una profesión más bien grotesca, lo que no significa que no sea para Kertész una cosa seria. Como dijera Nietzsche en Ecce homo: «No conozco ningún otro modo de tratar con tareas grandes que el juego» ${ }^{21}$.

\section{LA ESCRITURA Y LA VIDA}

«La mayor parte del pensar consciente [...] está guiada de modo secreto por los instintos», dice Nietzsche del filósofo ${ }^{22}$. Kaddish por el hijo no nacido ${ }^{23}$, tercera novela de Kertész, es como una erupción de los instintos, una mirada lanzada al abismo del tiempo.

Kaddish es el análisis hecho en voz alta de por qué el narrador no ha querido tener descendencia, de cómo se le ha impuesto el «contrainstinto»—expresión

19. I. Kertész, Fiasco, trad. de A. Kovacsics, Barcelona: Acantilado, 2003, p. 56.

20. Ibid., p. 12.

21. EH, trad. de A. Sánchez Pascual, Madrid: Alianza, ${ }^{6} 1980$, p. 54.

22. $\mathrm{MBM} \ 3,24$.

23. Obra escrita entre 1987 y 1989, se publica en 1990: I. Kertész, Kaddish por el hijo no nacido, trad. de A. Kovacsics, Barcelona: Acantilado, 2001. 
suya- de no prolongarse. Compuesto de 18 párrafos $^{24}$, cada uno de ellos comienza con un «iNo!» que grita, que chilla, que el infraconsciente hace aflorar. Largas páginas de memoria en que los acontecimientos y las reflexiones van encabalgándose con una energía incontenible, la de esos «noes» volcánicos que se imponen primero de manera instintiva, para al final articularse ya perfectamente: «no quiero —explicará a su mujer-que la infancia que a mí me ocurrió le ocurra - a otro niño... ${ }^{25}$.

Kaddish es, pues, la historia de una negación elaborada, «el camino largo —dice Kertész, y yo añadiría: siempre inacabado- de la verdadera lucidez $»^{26}$.

La reflexión completa vendría a ser, por un lado, la articulación de ese grito que es negación, negación instaurada en un cuerpo, negación que rige un destino a la manera - dirá el narrador - de un contrainstinto que hubiera devenido instinto en lugar del instinto. Así pues, articulación verbal, lingüística de un grito, por un lado. Por otro, y esto es lo esencial, esa articulación del grito sería asunción de la negación, es decir, encaje vital del carácter de latencia, de la positividad insoslayable de la negación. Dicho en otro registro: asimilación de que la existencia del individuo - la verdadera existencia - pasa por la admisión de la diferencia, del abismo que media («un telón de acero», dirá Kertész) entre dicha existencia y el lenguaje, diferencia, abismo que el lenguaje convencional, el lenguaje entendido en cuanto representación ya de entrada negaría. Por ello, la asunción vital de esa negación, que es reconocimiento del cuerpo, supondría al tiempo - exigiría - una transformación de la vivencia del lenguaje: de espejo rígido que niega lo que él mismo deja en sombra pasará a ser fluido maleado por la vida. Un lenguaje propio. Un lenguaje que responda a la experiencia, cuyo núcleo central es el dolor, la humillación, la soledad del individuo negado. Y ese lenguaje, y la integración del contrainstinto, se logran por medio de la escritura.

La escritura es, entonces, lucha, lucha consigo mismo, lucha con el mundo.

Ya desde que comienza a trabajar en su primera novela intuye Kertész que está trabajando en sí mismo, que lo que le hace a uno escritor es «no aceptar el lenguaje y los conceptos dados ${ }^{27}$, que no entiende, o, como dirá más adelante, el deseo de «reconquistar su individualidad arrebatándola a la historia» ${ }^{28}$. $\mathrm{Y}$ es que el lenguaje total — la «neolengua» de Orwell- se introduce en las conciencias individuales y expulsa al individuo de su propia vida interior. Así éste se adapta y —hombre funcional— sólo le queda sobrevivir. Lo que Kertész necesita para reconstruir su personalidad es el logro de un lenguaje personal. Lo que en el fondo no es sino una lucha sobre todo consigo mismo. Al final de Fiasco dice:

Más importante que su novela es para él lo que vivió por el hecho de escribirla. Fue una elección y una lucha, la forma de lucha que le estaba dada. Libertad dirigida contra él mismo y su destino, superación de las circunstancias, tentativa que minaba la necesidad... ¿Qué es, si no, la obra, cualquier obra humana? ${ }^{29}$.

24. En sentido estricto, ni párrafos, pues sólo dos de ellos tienen punto y aparte...

25. Cf. ibid., p. 112. Cursiva mía.

26. Ibid., p. 23.

27. I. Kertész, Diario de la galera, cit., pp. 19-20.

28. Ibid., p. 76.

29. I. Kertész, Fiasco, cit., p. 370. 
Lucha consigo mismo, contra la historia y la necesidad, libertad. Y es que la escritura, o la creatividad, es una función vital, como entendía Nietzsche ${ }^{30}$. La voluntad de poder como impulso de re-interpretar la realidad.

Es una función vital que se puede atrofiar, y cuando se atrofia hace de la vida mera supervivencia. En su caso, sin embargo, se ha convertido en necesidad. Por haber descubierto en ella precisamente esa posibilidad de ir alimentado la existencia, de ir transformándola en algo real, de objetivarla en obra.

La objetivación en obra permite recuperar la vida ${ }^{31}$, «trasmite existencia a la existencia ${ }^{32}$. En este sentido enfático cumple la fabulación de que hablaba Nietzsche una función vital: da vida a la vida, la recupera y la relanza, la arranca de sí para, al otro lado del abismo, recrearla. La escritura es vida potenciada ${ }^{33}$. Escribir es vivir dos veces: la primera vez, como esfuerzo más bien ciego; la segunda, como esfuerzo vidente, como esfuerzo de visión, puesto que supone pensar y cuestionarla, mas en definitiva darle forma, crearla ${ }^{34}$. Como dirá Merleau-Ponty, «los escritores no tienen la impresión de inventar, porque descifran los jeroglíficos de su paisaje, mas sí crean, puesto que esas verdades mudas tomadas del paisaje, nadie más las haría hablar»»3.

Así va entendiendo Kertész la escritura. La escritura le permite descubrir que la vida en el fondo es poder de creación, y que el autor, en realidad, no es sino la tierra en que surge la obra. Esto es lo que viene a sentir acerca de Fiasco, acaso valiéndose de la imagen que Nietzsche traza en La genealogía de la moral: «En última instancia [el artista] es tan sólo la condición preliminar de su obra, el seno materno, el terreno, a veces el abono y el estiércol sobre el cual y del cual crece aquélla» ${ }^{36}$. Kertész dice: «Fiasco creció en mí, se desarrolló en mí y se separó de mí como el fruto de una planta» ${ }^{37}$.

Naturalmente, eso supone una transformación de la vida en obra, y a la vez una transformación de la vida por la obra, la radicalización de la existencia. Escribiendo, los recuerdos se convierten en otra cosa:

30. «La creatividad — dice Kertész - no es un don divino venido de fuera, sino una función vital, el instrumento necesario para quedar con vida» (Diario de la galera, cit., p. 174).

31. Cf. I. Kertész, Diario de la galera, cit., p. 148.

32. Ibid., p. 209.

33. I. Kertész, Dossier K., cit., p. 59.

34. Cf. I. Kertész, Kaddish..., cit., pp. 58-59. «[...] la vida es un esfuerzo más bien ciego y la escritura, un esfuerzo más bien vidente que se distingue por tanto de la vida, claro, y que tal vez se esfuerza por ver aquello por lo que se esfuerza la vida y, como no puede hacer otra cosa, repite la vida de la vida, copia la vida como si ella, la escritura, fuese vida, y no lo es, no lo es de una manera fundamental, incomparable, de una manera, incluso, que no tiene parangón, de tal modo que, cuando nos ponemos a escribir, a escribir sobre la vida, el fracaso está de entrada garantizado».

35. M. Merleau-Ponty, Notes de cours 1959-1961, Paris: Gallimard, 1996, p. 203: «Les écrivains n'ont pas l'impression de créer, d'inventer, parce qu'ils sont en effet en train de déchiffrer [les] hiéroglyphes de leur paysage. Mais, ils créent parce que 1) ces vérités muettes prises dans leur paysage, personne ne les ferait parler à leur place...».

36. GM, trad. de A. Sánchez Pascual, Madrid: Alianza, ${ }^{2} 1975$, III, 4, p. 117.

37. I. Kertész, Diario de la galera, cit., p. 203. Camus tiene una concepción semejante de la obra de arte: «Hay cierta relación entre la experiencia global de un artista y la obra que la refleja, [...] Esa relación es buena cuando la obra no es sino un trozo tallado en la experiencia, una faceta de diamante cuyo brillo exterior se resume sin limitarse. [...] el gran artista es ante todo un gran ser vivo, si entendemos que vivir es tanto sentir como reflexionar» (El mito de Sísifo, trad. de E. Benítez, Madrid: Alianza, 1999, pp. 128-129). 
Se transformaron en contenidos de diversos cajones, donde rebuscaba cuando lo creía necesario [...]. Los hechos de mi vida, la llamada «materia de mi experiencia», ya sólo molestaban, dificultaban y limitaban mi trabajo, la creación de la novela a la que, en un principio, servían de base existencial. [...] Escribir la novela sólo consistía en el consumo de mis experiencias, en interés de una fórmula artificial —o, si se quiere, artística- que yo podía considerar adecuada a mis experiencias sobre el papel, única y exclusivamente sobre el papel ${ }^{38}$.

Crear es ordenar el caos constitutivo de la existencia, someterlo a una ley, la de la obra particular que sobre la experiencia se va labrando; y, de ese modo, reelaborándolo, deja uno atrás a aquel que era: fruto de determinaciones externas, "náufrago del azar, siervo de la electrónica biológica, hombre asombrado, muy a su pesar, de su propio carácter» ${ }^{39}$.

La radicalización consistiría en abrirse a ese caos y echar una mirada en el abismo de la memoria, dejando que el abismo hable; en otros términos, supondría dar una forma adecuada a esa voluntad de expresión que es el cuerpo, convirtiéndola en significación y sentido a través del trabajo y la reapropiación del lenguaje.

En La bandera inglesa, donde Kertész habla de la radicalización de su vida gracias a su encuentro con La Valquiria y el relato de Th. Mann inspirado en ella ${ }^{40}$, descubrimos que radicalizar la vida es literalmente hacerse cargo de la pasión, raíz de la existencia, y recrearla en obra, de modo tal que la formulación, la narración de su existencia no se contradiga con la propia existencia, con su forma de vida, o "al menos no [haya] una contradicción radical» ${ }^{41}$. Que no se contradiga..., es decir, que de algún modo se adecue la experiencia al papel, sin que eso signifique que entre la existencia y su formulación deje de haber un «telón de acero» — dice él一, ese telón de acero que separa al hombre de sí mismo. O, como lo formula Diego Sánchez Meca, ese abismo de separación que hay entre mí mismo como ser vivo que siente y yo mismo como ser cultural que toma conciencia e interpreta ese sentimiento, abismo que ningún puente une ${ }^{42}$. Narrar sin que quede cegado el abismo: ésa sería la única forma de decir la verdad, esto es, de no mentir demasiado. Por eso, al final de Fiasco dirá que escribir es «destilar en signos la realidad inefable» ${ }^{43}$.

Si lo miramos del lado de la vida, lo que encontramos no es silencio y vacío, sino fuerza creativa, voluntad de expresión. Atendiendo a la pasión, entregado al trabajo de creación se descubre algo otro en uno mismo. Van Gogh lo expresó a la perfección: «Puedo prescindir perfectamente de Dios en la vida y en la pintura, pero enfermo y todo no puedo prescindir de algo que es más grande que yo, que es mi vida: el poder de crear ${ }^{44}$.

38. I. Kertész, Fiasco, cit., p. 78 .

39. Ibid., p. 59.

40. Th. Mann, "Sangre de Welsungos", en La voluntad de ser feliz y otros relatos, trad. de R. Sala, Barcelona: Alba, 2001; en concreto, p. 367: «vio su amor y su necesidad y sintió que la vida, para ser creativa, tenía que ser así" (en cursiva lo que Kertész cita en La bandera inglesa, trad. de A. Kovacsics, Barcelona: Acantilado, 2005, p. 41).

41. Cf. I. Kertész, La bandera inglesa, cit., p. 55.

42. «Entre mí mismo como ser vivo que siente y yo mismo como ser cultural que toma conciencia e interpreta ese sentimiento hay un abismo de separación que no une ningún puente (keine Brücke)» (D. Sánchez Meca, Nietzsche. La experiencia dionisíaca del mundo, Madrid: Tecnos, 2005, p. 138).

43. I. Kertész, Fiasco, cit., p. 370.

44. I. Kertész, Diario de la galera, cit., p. 131. Cursiva mía. 
Kertész vive la prepotencia y multiplicidad de la vida:

Sería un error suponer que mi vida es mía. Pero un error todavía más grande sería abandonarla, estropearla, echarla a perder. Esta vida me ha sido confiada. [...] Mantengo una relación de reciprocidad con mi vida. ¿El nombre de esta relación? Servidumbre. Hasta aquí todo bien. Pero équé partícula de esta vida fragmentada se refiere a sí misma con la palabra «yo»? ${ }^{45}$.

La lucha que esa serie de fuerzas infraconscientes, la vida prepotente y múltiple, desarrollan, en principio de manera imperceptible, ascendiendo luego de las profundidades insondables de la existencia hasta la superficie de la conciencia, es la que trata de narrar la escritura de Kertész ${ }^{46}$. Por eso, uno de los epígrafes de Yo, otro, todo un librito dedicado a la inconsistencia del sujeto, dice: "Yo': una ficción de la que a lo sumo somos coautores» ${ }^{47}$.

Y no se trata de coquetería posmoderna. De la visita que realiza en los años noventa a Buchenwald anota: «Merece la pena visitar los escenarios en que se produjeron los acontecimeintos decisivos de nuestras vidas, porque así tomamos conciencia de que no tenemos nada que ver con nosotros mismos» ${ }^{48}$.

Radicalizar la existencia supone, entonces, exponerse a esa fuerza múltiple y desconocida que es nuestra vida y a la vez, mediante la escritura, intentar guiarla en pos de sí misma. Tensión en dos direcciones que Nietzsche ya había anticipado al decir, por un lado, que el arte de verdad es el que estimula, el que impulsa en todo momento la vida ${ }^{49}$, y, por otro, que lo "esencial en el arte es que consuma la existencia, haciendo que sea perfecta y plena ${ }^{50}$.

\section{EL TIEMPO: LA DECISIÓN: SER UN PARTICULAR}

Hay una breve anotación hecha por Heidegger en 1922 al margen de un texto sobre Aristóteles que siempre me ha resultado muy esclarecedora. Dice: «Zeitlichkeit — Tod — entscheidende Einmaligkeit!» ${ }^{51}$.

45. I. Kertész, Yo, otro. Crónica del cambio, trad. de A. Kovacsics, Barcelona: Acantilado, 2002, pp. 12-13. También: «Mi vida absurda y entregada resulta incomprensible e insondable. El impulso vital la empuja y mi llamada personalidad trata de dirigirla. Pero ¿quién o qué la enyuga, y para qué? Es un misterio. A todo esto, el abismo entre yo y yo se abre cada vez más» (Diario de la galera, cit., p. 261).

46. Cf. I. Kertész, Yo, otro, cit. p. 110.

47. Ibid., p. 5.

48. Ibid., p. 69.

49. KSA XIII 228: 14[23], primavera de 1888. Dice esto reinterpretando la «metafísica de artista» de El nacimiento de la tragedia.

50. KSA XIII 241: 14[47], primavera de 1888: «das Wesentliche an der Kunst bleibt ihre Daseins-Vollendung, ihr Hervobringen der Vollkommenheit und Fülle. Kunst ist wesentlich Bejahung, Segnung, Vergöttlichung des Daseins...».

51. Y continúa: «Dieses 'Einmal' ist radikal 'Alles' des Lebens. Zeitlichkeit nicht wie Quantitäten und solches Nacheinander, sondern existenziell faktische Sprünge. Die Kontinuität imgleichen je ein Sprung (proaíresis!), imgleichen das Wie des Erwartens» ["Este 'una vez' es radicalmente el 'todo' de la vida. La temporalidad no como cantidades y tal sucesión, sino existencialmente saltos fácticos. Del mismo modo, la continuidad en cada caso un salto (iproaíresis!), igual que el cómo del esperas»]. Cit. por T. Kisiel, The Genesis of Heidegger's Being \& Time, Los Angeles: University of California Press, 1993, p. 538, nota 20. 
En el espejo difrangente de la muerte, el tiempo es Einmaligkeit, todo es una sola vez. La continuidad del tiempo está, en definitiva, hecha de saltos, el salto de la proaíresis, la de-cisión aristotélica, que es a la vez elección y anticipación.

Dicha continuidad discontinua es la que permite que nos hagamos cargo del pasado en cuanto espacio de posibilidades en que ir trazando el futuro. Por lo que hace a la escritura y reescritura de la propia vida, intuyo que no difiere mucho esta idea de la interpretación que Manuel Barrios propone de la idea del eterno retorno: «Ninguna narración agota el sentido de lo narrado, porque el acontecer nunca llega a ser enteramente pasado ni queda clausurado». No se trata de que se repita el mismo tema, sino de que "con cada relatar se repite la posibilidad de volver a contar lo acontecido como por primera vez». Y es que cada vez es propiamente la primera si nos entregamos a ella. "Lo que se repite a cada instante es la posibilidad de re-comenzar, de cortar el hilo de mera sucesión lineal y prosecución de lo antecedente, para abrirse a un nuevo acontecer $»^{52}$.

Es la decisión, pues, el corte, lo que estructura el tiempo, y lo que permite que éste, liberado de la rigidez de la causalidad, pueda plegarse, reuniendo en el presente pasado y futuro, y adquiriendo así densidad, profundidad. $Y$ así ha sido en el caso de Kertész.

Su aventura comienza a finales de 1955 — dice en Dossier K.—, cuando vivió lo que él mismo llama «iluminación», cuyo efecto fue el que, neurótico, desesperado y como poseso, en definitiva, se pusiera a escribir. En cualquier caso, dicho éxtasis icambió su vida! En julio de 1964 anotaba en el Diario de la galera: «En la vida del ser humano hay un instante en que de pronto toma conciencia de sí mismo, y sus energías se liberan; a partir de ese momento podemos contar nuestro tiempo». Y advierte: «Pero no toda persona es capaz de convertir su vida en su propia vida $»^{53}$.

Toma de conciencia, decisión por uno mismo.

En Estocolmo habló de la experiencia en estos términos:

[Frente al axioma filosófico de que el mundo es la realidad objetiva que existe independientemente de nosotros:] Un espléndido día de primavera de 1955 comprendí de repente que sólo existía una realidad, yo, mi vida, este regalo frágil de duración incierta [...] que yo había de recuperar del Moloc monstruoso llamado Historia, porque mi vida sólo me pertenecía a mí y debía disponer, por tanto, de ella ${ }^{54}$.

La experiencia de iluminación en el pasillo en L aparece en Fiasco dos veces: en la primera se produce una decisión por el arte, en la segunda el giro es de carácter existencial. Vienen a ser lo mismo: el giro existencial consiste en ponerse a escribir, en salir de su «vida anónima» escribiendo una novela, respondiendo a una pulsión que le domina ${ }^{55}$.

La iluminación en sí tiene dos momentos: el primero es la tentación de la muchedumbre, de la masa: «el calor, la seguridad, [...] y la felicidad difusa del

52. M. Barrios Casares, Narrar el abismo. Ensayos sobre Nietzsche, Hölderlin y la disolución del clasicismo, Valencia: Pre-Textos, 2001, p. 196.

53. I. Kertész, Diario de la galera, cit., p. 16, julio de 1964.

54. I. Kertész, «iEureka!», en La lengua exiliada. Artículos y discursos, trad. de A. Kovacsics, Madrid: Taurus, 2007, p. 146.

55. Cf. al respecto A. Kovacsics, «Kertész y la decisión por el arte»: Archipiélago 82 (2008), $35-41$. 
olvido eterno» ${ }^{56}$. Lo que Kertész equipara a la experiencia de lo dionisíaco. Frente a eso, y en un segundo momento, se encuentra "su vida abandonada y sin dueño ${ }^{57}$, su singularidad. Y ni siquiera tiene que elegir: la vida le empuja a ser él. «Él» se opone aquí a su disolución en la masa, al hombre funcional que sólo sobrevive, sin saber acaso qué sea vivir. Pues vivir es ordenar un mundo o al menos acotarlo, no perderse en él; y el gran arte de la existencia, podemos decirlo con las palabras que Nietzsche dedica al «gran estilo», es «hacerse cargo, hacerse dueño del caos que uno es» ${ }^{58}$.

Ese hacerse cargo de la propia vida no supone negar el mundo, todo lo contrario:

Le había ocurrido un vuelco irrevocable — continúa Fiasco-: todo cuanto había sucedido y sucedía, le había sucedido y le sucedía a él, y no podía suceder nada en el futuro sin esta conciencia tajante. [...] Así debería vivir a partir de ahora, con la mirada clavada en la existencia ${ }^{59}$.

En vez de, como el último hombre, parpadear.

De la tentación de disolución en la masa surge un particular que se hace cargo de su existencia, antes abandonada y sin dueño, una conciencia tajante, una mirada atenta, para la cual nada es ajeno: todo lo que suceda, le sucede a él. Es más, el suceder le hace, le constituye, le confiere su ser más propio. Esa decisión, esa toma de conciencia existencial viene a ser un cogerle el ritmo al tiempo, un dionisíaco decir sí a la existencia.

Pues, efectivamente, tras el éxtasis, al salir a la calle, esa elección de sí mismo, que va a ser una manera de atender y cuidar la existencia, de mirar el tiempo en su densidad y honduras, toma la forma de aprobación: son unas pancartas que dicen: «iQueremos vivir!», las que aprueba, «del mismo modo que aprobaba, por ejemplo, la luz del sol ${ }^{60}$. Aprobación, de la vida: en su multiplicidad, energía y voluntad de afirmación.

Es aquella decisión, reiterada una y otra vez, la que va dando sentido a la existencia de Kertész, sentido que no implica continuidad, clausura del tiempo, sino - jugando un poco con esa palabra tan rica y maravillosa para la especulación- ojos para sus grietas, oídos para sus gritos callados, tacto para la textura de la vida, en definitiva, saber tratar con la contingencia y el azar.

En su autobiografía, Dossier K., da cuenta - precisamente- de la contingencia de su vida, "de la vergonzosa casualidad de cada instante» ${ }^{61}$. A diferencia de las autobiografías al uso, lo que en ella sale a la luz no es la continuidad, el proceso de formación, sino una historia tejida de azar y necesidad, si se quiere, de absurdo y casualidad, a la que lo único que da sentido — valga aquí ahora como dirección y guía- es la elección existencial del autor. Recordemos la radicalización de su juventud (narrada en La bandera inglesa), la iluminación de Fiasco, la asimilación del «ino!», el dolor y el abismo interior de Kaddish y, por

56. I. Kertész, Fiasco, cit., p. 363.

57. Ibid., p. 363.

58. KSA XIII 247: 14[61]: Über das Chaos Herr werden das man ist.

59. I. Kertész, op. cit., pp. 364-365.

60. Ibid., p. 365.

61. I. Kertész, Yo, otro, cit., p. 121. 
último, el nuevo recomienzo que Liquidación trasluce, al borde ya del siglo xxi: sólo «suicidando» a uno de sus alter ego en esta su cuarta novela, logró Kertész librarse de la obsesión por el suicidio y se dispuso a volver a recomenzar.

Kertész se ha pasado la vida digiriendo el absurdo, tejiendo el azar, dando forma al caos del mundo, es decir, afrontando la muerte ${ }^{62}$. En Sin destino, cuando Köves se había ya reconciliado con la muerte inminente, «el olor inconfundible de la sopa de zanahoria» de Buchenwald le despertó el deseo de vivir «un ratito más en este campo de concentración tan hermoso" ${ }^{63}$. La lección que el azar en esta ocasión le dio la aprendió bien. Por eso, nunca ha dejado de redimir el pasado. De ese modo ha ido forjando su destino, haciéndose cargo, adueñándose de su facticidad fuera la que fuera, guiado, podemos decir, por la fórmula vital que Nietzsche llamó amor fati.

De ese modo se convierte uno en lo que era. En el caso de Kertész, a través de la escritura. Por eso dice en algún lugar que sólo posee identidad en el escribir $^{64}$, una identidad, por lo tanto, cambiante, que se pierde, se olvida y abandona, renace transformada, como el curso de la escritura, como el trazo del tiempo. Nada, pues, realmente que merezca el nombre grave de identidad. Afrontar la muerte es asimilar la extrañeza de ser, vivir — también- en lo extraño.

En realidad, cuando Kertész nos dice que sólo en el escribir posee identidad, nos está diciendo que sólo escribiendo encuentra su propia vida, una existencia verdadera, «un campo de fuerzas coherente» - dice- que informa en el fondo cierta organicidad, un modo de unidad vital; no sé si estará hablando de aquella roca granítica que para Nietzsche es el fatum espiritual ${ }^{65}$. Lo que sí está claro es que en la escritura Kertész no sólo da testimonio de su vida, sino que, además, la redime, convirtiendo todo su dolor en alegría. Y eso es gozar la vida: intensidad y fuerza, poder. «[...] mi aventura más grande soy yo, a pesar de todo», confiesa en el Diario de la galera ${ }^{66}$.

Decía Nietzsche que «la medida de la fuerza de la voluntad la da el grado en que se puede prescindir de un sentido en las cosas, el grado en que se soporta vivir en un mundo sin sentido" ${ }^{67}$. Eso es lo que Kertész ha hecho y sigue haciendo. Hemos visto ya — creo- cómo lo hace con su obra. Su risa, una risa — dice Péter Esterházy - de naturaleza cósmica, llena de fuerza y desesperación, de dicha y de soledad; una risa, en fin, que es el jubiloso estremecimiento del cuerpo ante la vista del sinsentido; su risa, si la oyéramos, nos lo haría entender de golpe.

62. Cf. I. Kertész, Dossier K., cit., pp. 75-76.

63. I. Kertész, Sin destino, cit., p. 192: «un ligero deseo que acepté con vergüenza, el deseo de seguir viviendo, por otro ratito más, en este campo de concentración tan hermoso».

64. I. Kertész, Yo, otro, cit., p. 63: «sólo poseo una identidad, la identidad del escribir (Eine sich selbst schreibende Identität)».

65. Cf. MBM $\ 231,181$.

66. I. Kertész, Diario de la galera, cit., p. 149.

67. KSA XII 366: 9[60] (FP IV 250). 